\title{
A NEW GENUS OF PHYLLOMYZINAE (DIPTERA: MILICHIIDAE) FROM LAOS AND VIETNAM
}

\author{
LÁSZLó PAPP \\ H-1182 Budapest, Beremend u.43, Hungary; E-mail: flyer.papp@gmail.com
}

A new genus of the phyllomyzine Milichiidae, Indochinomyia gen. n. (type species: I. viet sp. n.) is described. Also an additional species from Laos (I. lao sp. n.) is described. The peculiarities of the new genus are discussed. With seven figures.

Key words: Milichiidae, Phyllomyzinae, Indochinomyia, taxonomy, new species, Laos, Vietnam.

\section{INTRODUCTION}

The dipterous family Milichiidae is one of the best known acalyptrate flies. Even Hennig (1937) made a much higher level summary on them than on most of the families in the series on Palaearctic flies. SABrosky (1987) kept the genus concepts clear and he produced fine papers on several genera. Finally BRAKE (2000) in her monograph of the phylogenetic systematics of Milichiidae defined subfamilies and genera and she proposed a phylogenetic tree based on adult characters. Her magnum opus makes easy to recognise any genus, and in addition, the list of the known species was also included.

In the last decades the extensive collections of the co-workers of the Department of Zoology of the Hungarian Natural History Museum in the Old World tropics, particularly in the Oriental region, resulted in an accumulation of interesting material there. Most recently one female each of two species of Milichiidae (subfamily Phyllomyzinae) was found there, which do not fit to any of the genera in BRAKE's (2000) monograph.

\section{MATERIAL AND METHODS}

Specimens are double mounted on minuten pins. Abdomen of the holotype of I. viet was prepared with hot sodium hydroxide and lactic acid, carefully washed in water and stored in a plastic microvial with glycerine pinned below the specimen. The preparations were positioned under an OLYMPUS SZ-ST stereomicroscope usually under 100× magnification; figures were made from glycerol under a normal cover glass put over glycerol on a slightly hollowed microscopic slide. Drawings were prepared on an OLYMPUS BX40 microscope with an OLYMPUS U-DA device under 333× magnification. The holotypes were photographed with a Nikon D200 camera with Olympus 5× Plan objective. A large series of pictures were captured (appr. 120 consecutive images with different focal depths), then the series of photos were combined with Zerene Stacker software. 
Terminology follows the Manual of Palaeartic Diptera and Brake (2000), except for wing venation (see PAPP 2010).

The type specimens are deposited in the Diptera Collection of the Department of Zoology, Hungarian Natural History Museum, Budapest (HNHM).

\section{TAXONOMY}

\section{Indochinomyia gen. $\mathrm{n}$.}

(Figs 1-7)

Type species: Indochinomyia viet sp. n., by present designation.

Gender: feminine.

Additional species: Indochinomyia lao sp. $\mathrm{n}$.

Diagnosis. Medium-sized (2.8-3.25 mm) shiny black flies (Fig. 1) with clear, possibly hyaline, wing and simple legs in the subfamily Phyllomyzinae. Head in profile subquadrate, vertical diameter of eye less than 1.5 times as long as horizontal diameter, epistoma not extended dorsally, vibrissa below lowest edge of eye, postocellar setae very long, apices crossing, basisternum small, wing without subcostal notch, veins $R_{4+5}$ and $M_{1+2}$ not converging towards wing tip, cubital cell terminates acutely (i.e. not rounded), hind basitarsus with a posterior comb of thin sharp setae.

Description. Head. Occiput only slightly concave. Proboscis not elongate, labella shorter or much shorter than head. Antennae not far from each other (Fig. 4). First flagellomere extremely large in female (Figs 2-3), most probably also in male, i.e. first flagellomere much larger than pedicel. Actually 3 lateroclinate long orbital pairs, posterior one far from the 2 anterior pairs and close to inner (medial) vertical seta, orbital plate strongly oblique and anterior orbital seta much medial to and slightly anterior to posterior frontal seta (I. viet), or, orbital plate less oblique and fused with frontal plate into a very broad shiny rim of eye (I. lao, Fig. 4); some other thin frontal setae present. Frontal vitta (interfrontal stripe) finely hatched (Fig. 4) broad, terminates broadly above lunule (Fig. 4) with a pair of supra-antennal setae most anteriorly, lunule small with a pair of short setae. No interfrontal setae or only a few unpaired hairs in interfrontal position. Ocelli comparatively large, distance of hind ocelli less than 2 times larger than diameter of fore ocellus. Scape very small, pedicel with a long dorsal apical seta. First flagellomere without long cilia, arista with scattered very short $(0.015 \mathrm{~mm})$ rays. Vibrissal angle sharp, mouth margin more or less protruding (Figs 2-3).

Thorax. Strongly convex, mesonotum strongly shiny. Only 1 postpronotal seta, 1 long presutural, 2 notopleural, 1-2 posterior dorsocentral, 2 supra- and 2 post-alar each (1 very large posterior supra-alar, 1 strong post-alar in intra-alar position) pairs of setae. 2 pairs of scutellar setae, no discal scutellar setulae. Acrostichal microchaetae numerous and not ordered in regular rows, emerging from small swellings. No enlarged prescutellar acrostichal pair present. 
Wing. Costa with 2 costal breaks similarly to other Milichiidae, humeral break as far from humeral vein as the length of humeral vein, costal vein extending to vein $\mathrm{M}_{1+2}$. Third and fourth costal sections about equally long, second costal section 6 to 7 times as long as third section. No notch or stronger fringe on costa. Cross-vein R-M at about middle of discal cell. Distal section of $\mathrm{M}_{3+4}$ reaches wing margin. Alula rather large (almost as broad as discal cell), with medium long marginal setae; otherwise as in the diagnosis.

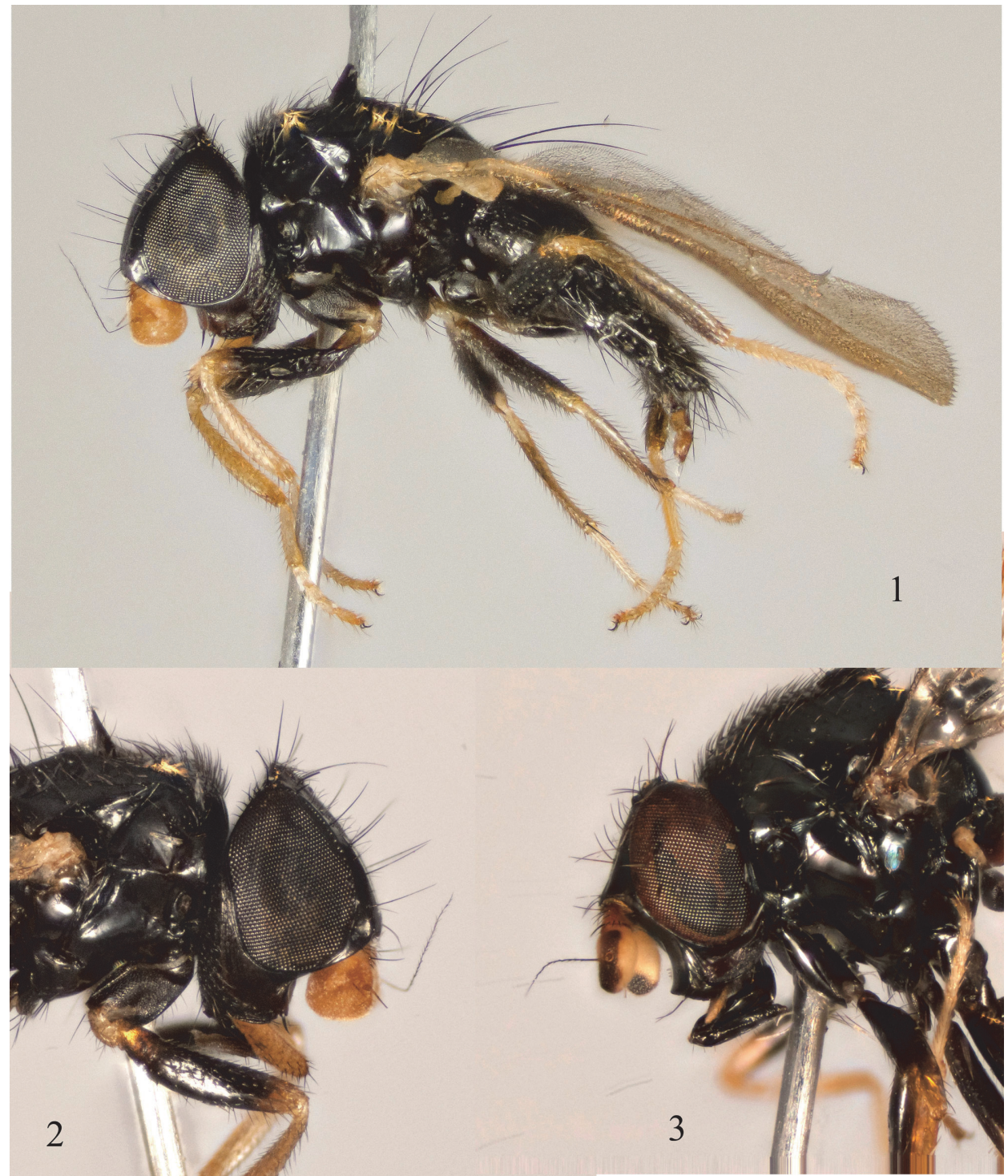

Figs 1-3. Indochinomyia gen. nov., holotype females. 1 = I. lao sp. n., habitus; 2 = I. lao sp. n., head laterally; $3=$ I. viet sp. n., head laterally. 
Legs. Simple, mid tibia with a long straight apical spur. Hind basitarsus with a complete comb of straight rather thin short setae.

Female abdomen and genitalia. Abdomen not telescopised (i.e. intersegmental membranes short). Abdominal tergites $1+2$ occupies $1 / 3$ of abdominal length. Preabdominal sternites only $1 / 6$ width of tergites or so. Tergite 7 and tergite 8 not divided, tergite 8 seems slightly asymmetrical (Fig. 7). Cercus very small oblique with medium-long setae only (Figs 6-7), epiproct (supra-anal plate, tergite 10) short and very broad with 1 pair of fine setae (Fig. 6), hypoproct (subanal plate, sternite 10) large (Fig. 7) although weakly sclerotised.

Male unknown.

Etymology. The name of the new genus composed of the name of the territory of the collection of its species (Indochina) and of the Greek 'myia' (= fly).

Discussion. This new genus keys to couplet 10 in Brake's key to genera of Milichiidae (see Diagnosis): Indochinomyia gen. nov. is not closely related to Borneomyia Brake, 2004. Although the male sex has been unknown, it seems improbable that the male flagellomere would be larger than in the holotype females. Hind femur is without a femoral organ. When reaching couplet 10, none of the two branches fit to the new genus: Occiput only slightly concave, first flagellomere much larger than pedicel, lunular pair of setae minute. The comparatively large shiny black body (Fig. 1) makes the new genus conspicuous at a first glance.

After all, I think the closest relative of Indochinomyia gen. $\mathrm{n}$. is the genus Phyllomyza Fallén. However, it has no interfrontal setae (or a few scattered hairs there), female postabdomen is not telescoping at all, neither tergite 7 nor tergite 8 is divided (the latter is slightly asymmetrical but it is not sure that is a general feature), hypoproct (subanal plate) is very large (Fig. 7) contrarily to Phyllomyza females, epiproct (supra-anal plate) very short but broad. It is a matter of course that a discovery and study of the male sex will widen the differences.

\section{Indochinomyia viet $\mathrm{sp} . \mathrm{n}$.}

$$
\text { (Figs 3, 6-7) }
$$

Holotype, female (HNHM): VIETNAM, Lao Cai Prov., Hoang Lien NP, Tram Ton, along and over a small stream, sweeping - Apr 9-11, 2010, 22.346499 ${ }^{\circ} \mathrm{N} 103.7690706^{\circ} \mathrm{E}$, 1904 m, VN2010PL_5, leg. Papp, L. \& Soltész, Z. Abdomen prepared and kept in a plastic microvial with glycerol.

Description. Measurements in mm: body length 2.80, wing length 2.95, wing width 1.23. The two species found are rather far from each other, most of the features analysed are different. So it seems practical to summarise them in a table (Table 1).

Etymology. The specific epithet of the new species refers to the name of the people, whose country is its type locality. 
Table 1. Comparison between characters present in the two species of Indochinomyia gen. n.

Indochinomyia viet
Postfrons not lengthened, head in the level
of lunule only $11 / 3$ longer than at the level
of vibrissa (Fig. 3)
First flagellomere much longer than broad,
more ovoid than quadrate
Vibrissa setiform, as long as $1^{\text {st }}$ flagellomere
(Fig. 3 )
Palpus bacilliform, not swollen, less than $1 / 2$
of the fore tibial width
Outer (lateral) vertical seta small
No interfrontal setae
Only 1 pair of intra-ocellar setae
Postoculars pale and not longer than width
of interfrontal stripe
In lateral view gena only $1 / 5$ of the height
of eye

A few genal setae shorter than $0.10 \mathrm{~mm}$ only

Thoracic setae pale

1 pair of dorsocentral setae

Scutellum convex, strongly shiny

Wing hyaline, veins yellow, membrane on all ventral side and mostly on dorsal side non-microtrichose, some microtrichia in a medial stripe of $\mathrm{r}_{4+5}$ and of discal cell and in apical section of $\mathrm{m}_{1+2}$; wing margin downwards vein $\mathrm{M}_{3+4}$ largely but sparsely microtrichose

Knob of halter black

Apical 2/3 of hind tibia black

\author{
Abdominal setae whitish \\ Abdominal tergites with very few setae \\ other than marginals \\ Female cercus with short (max. $0.05 \mathrm{~mm}$ ) \\ setae
}

Postfrons lengthened, head in the level of lunule much longer than at the level of vibrissa (Fig. 2), ratio $12 / 3$

First flagellomere quadrate, higher than long

Vibrissa very short and thick, shorter than pedicel (Fig. 2)

Palpus enlarged (Fig. 2), broader than fore tibia

Outer (lateral) vertical seta large (Fig. 4)

A few unpaired hairs in interfrontal position

Numerous short intra-ocellar setae

Postoculars dark and much longer than with of interfrontal stripe

In profile gena c. $1 / 3$ of the height of eye

Numerous genal setae, some of them longer than $0.15 \mathrm{~mm}$

Thoracic setae dark

2 pairs of dorsocentral setae

Scutellum flat and rugose

Wing clear, veins ochre, membrane covered by longish dense microtrichia on both ventral and dorsal sides (Fig. 1)

Knob of halter white

Only dorsal half of apical $1 / 2$ of hind tibia dark

Abdominal setae dark

Abdominal tergites covered by short setae

Female cercus with long $(0.15 \mathrm{~mm})$ setae 


\section{Indochinomyia lao sp. $\mathrm{n}$. \\ (Figs 1-2, 4-5)}

Holotype, female (HNHM): LAOS, Xiang Khouang Prov., Ban Xay, disturbed mixed Pinus merkusii and broadleaved forest, $1115 \mathrm{~m}, 1^{\circ} 33.214^{\prime} \mathrm{N}, 1^{\circ} 3^{\circ} 3.127^{\prime} \mathrm{E}$, Febr. 14, 2012, light trap, No. LAO2012PL_17, leg. Peregovits \& Szappanos.

Description. Measurements in mm: body length 3.25, wing length 3.00, wing width 1.31. For detailed description see Table 1.
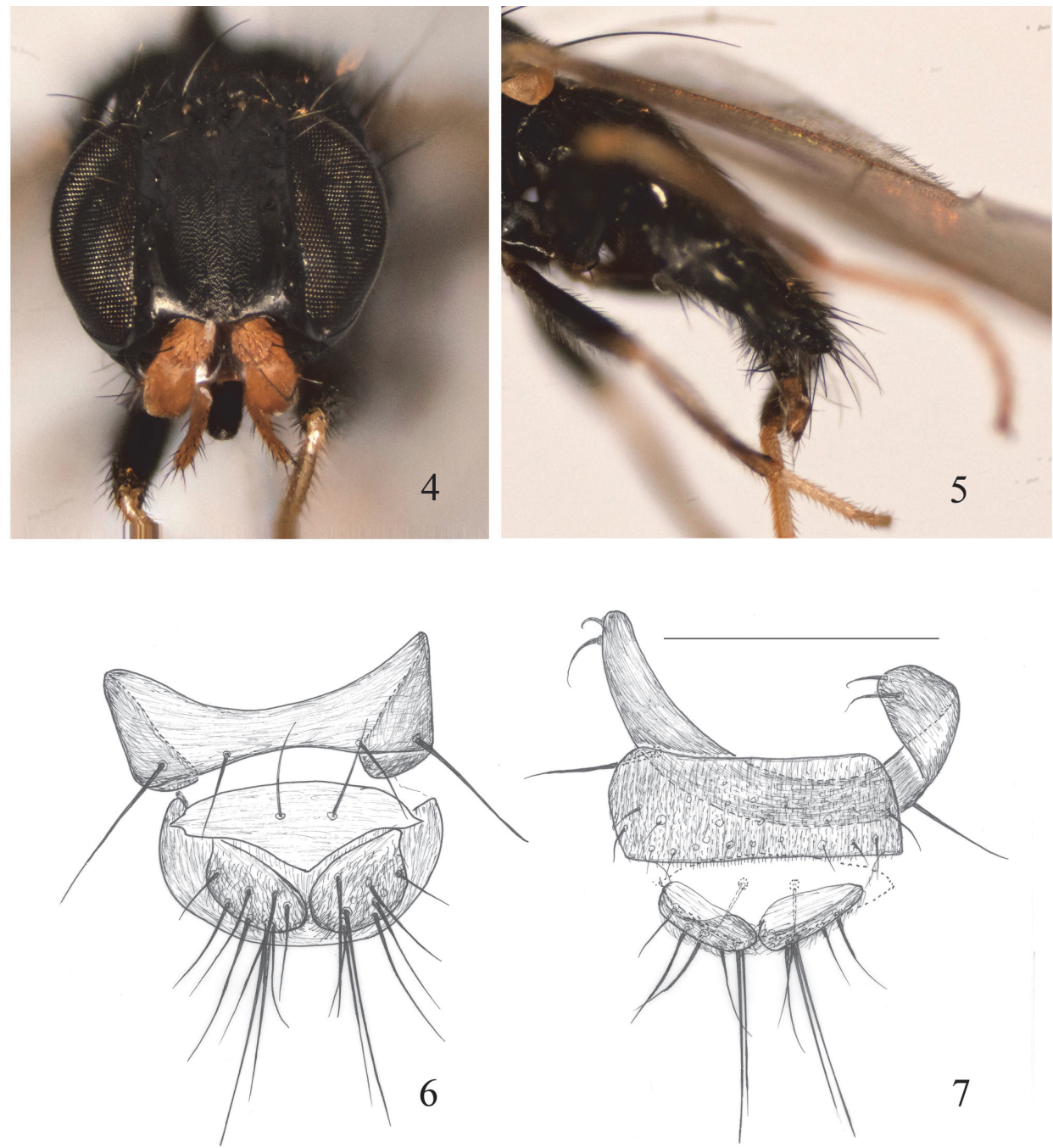

Figs 4-7. Indochinomyia gen. nov., holotype females. $4=$ I. lao sp. n., frons dorsally, $5=$ abdomen laterally; $6=$ I. viet sp. $\mathrm{n}$., female terminalia dorsally, $7=$ same, ventrally. Scale: 0.2 mm for Figs 6-7. 
Etymology. The specific epithet of the new species refers to the name of the people, whose land and country is its type locality.

Acknowledgements - I would like to thank Dr Irina Brake (NHM London) for advice. I am grateful to Zoltán Soltész (Budapest) for his help with the photos and plates.

\section{REFERENCES}

Brake, I. (2000) Phylogenetic systematics of the Milichiidae (Diptera, Schizophora). Entomologica Scandinavica (Insect Systematics \& Evolution) Supplement 57: 1-120.

BraKe, I. (2004) Borneomyia, a new genus and two new species of Milichiidae (Diptera, Schizophora). Zootaxa 627: 1-8.

Hennig, W. (1937) 60a. Milichiidae et Carnidae. In: Lindner, E. (ed.): Die Fliegen der palaearktische Region, 6(1), 1-91. E. Schweizerbart'sche Verlagsbuchhandlung, Stuttgart.

PApp, L. (2010) A new Cremifania species from Bulgaria (Diptera, Cremifaniidae), with a proposal for wing venation terms in higher Diptera. Annales historico-naturales Musei nationalis hungarici 102: 193-204.

Sabrosky, C. W. (1987) Chapter 79. Milichiidae. Pp. 903-908. In: McAlpine, J. F. et al. (eds): Manual of Nearctic Diptera. Vol. 2. Research Branch, Agriculture Canada, Ottawa. Agriculture Canada, Monograph 28.

Received November 11, 2015, accepted February 25, 2016, published October 6, 2016 


\title{
Contributions to a Manual of Palaearctic Diptera
}

\author{
Edited by L. Papp and B. Darvas \\ Volumes 1-3, Appendix
}

The excellently illustrated volumes of the "Contributions to a Manual of Palaearctic Diptera" morphological, physiological, genetical, ecological and economic up-to-date knowledge of dipterous species (midges and flies), which have significant importance in genetics as model organisms, in plant cultivation as pests or beneficial parasitoids, in animal husbandry and human health as vectors of serious illnesses and which are important for ecosystem function, are treated. Morphological keys to generic level for adults and larvae are provided, which help readers with identification of dipterous pests and parasitoids, while readers in the field of applied dipterology will find suitable environmentally friendly methods against pests or biological control methods.

Volume 1 (published in 2000): 24 chapters of general and applied dipterology, by 31 specialists, on 978 pages with 956 figures on 176 plates. Volume 2 (published in 1997): 38 dipterous family chapters, by 23 specialists, on 592 pages with 1895 figures on 258 plates. Volume 3 (published in 1998): 56 dipterous family chapters, by 32 specialists, on 880 pages with 1773 figures on 294 plates. Appendix (published in 2000): 16 dipterous family chapters, by 19 specialists, on 604 pages with 2134 figures on 207 plates.

\section{ISBN 9630488361 (Series) \\ ISBN 9630488396 (Volume 1) \\ ISBN 963048837 X (Volume 2) \\ ISBN 9630488388 (Volume 3) \\ ISBN 963048840 X (Appendix)}

Foundation for the Publicity of the Hungarian Science

Publisher: Science Herald, Budapest

Order should be sent to

NEST Foundation, Collegium Budapest

Ms Szilvia Zimber, E-mail: szimber@colbud.hu 